\title{
The free risk rate of return and factors that affect its assessment
}

\author{
Diana Boskovska ${ }^{1}$

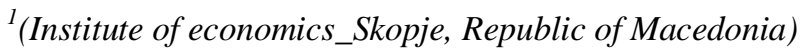

\begin{abstract}
The cost of capital is a key variable in the financial analysis because it provides adequate assessment of the value of capital, and the value of individual securities. Hence, the important question is how to determine the cost of capital. Initial basis for determining the cost of capital is a determining risk free rate of return that is subject of research in the paper. Risk free rate of return exists when the expected rate of return is known with certainty, that means that realized proceeds of an asset is equal to the expected yields of the same asset. Rate of return on that asset is characterized as risk-free rate of return. To be able to adequately determine the risk free rate of return is necessary to determine the factors affecting its value, such as the currency in which it is expressed risk free rate of return and inflation. Therefore, the paper explored the reasons that may lead to inadequate assessment of the risk free rate of return due to inadequate treatment of the impact of currency and inflation in the analysis.
\end{abstract}

Keywords - securities, cost of capital, free risk rate of return, currency, inflation.

\section{INTRODUCTION}

The numerous model od assessment of risk and rate of return start with a financial asset that is defined as the risk-free asset and therefore the expected return of that asset is used as a risk-free rate of return. Then, the expected returns of risky investments are determined in relation to the risk free rate, by adding expected risk premium.

To understand what makes an asset as a risk free asset, it is necessary to consider the way of the risk is measured in investment decisions. Investors who buy assets (financial or real) expect to achieve a yield in the period in which they plan to hold the asset. Realized yields that investors will achieve in a given period may vary and differ from expected returns as a result of the risk that carries the appropriate investment. To some an investment to be characterized as risk-free it needs the realized yields always to be equal to the expected yield, see Fig. 1.

Such investment is risk free because the realized returns do not vary around the expected yield, i.e. the standard deviation of realized yields in terms of the expected return is equal to zero [1].

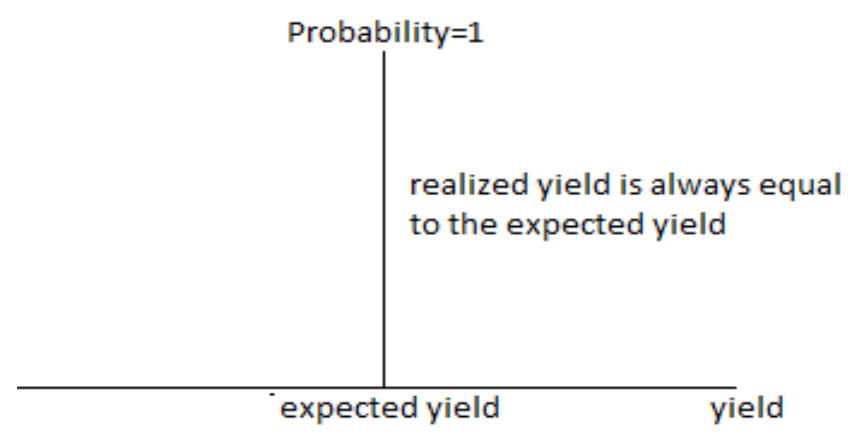

Figure 1 Rate of return of free risk investments [2]

\section{The Role Of The Free Risk Rate In The Financial Analysis}

Risk free rate is the basis to assess the cost of equity and the cost of total capital. The cost of equity is calculated so that to the risk free rate of return is added the risk premium, whose size is determined by the risk that carries the actual investment and total risk premium of equity (investments with an average risk). The cost of debt is calculated in such a way that to the risk free rate of return the default spread is added, whereas the size of it depends by the credit rating of the company. Since the cost of capital is dependent of the risk free rate of return, the use of higher risk-free rate increases the discount rate and reduces the present value in the valuation process through the method of discounted cash flows.

Risk free investment can be considered in a different way also, considering the correlation between its returns and the returns of other risky investments. Returns of the risk free investment is needed not to be in correlation with the returns of other risky investments on the market. The fact that the risk free investment 
provides a guaranteed yield implicitly means that its yield is not correlated with the returns of other risky investments on the market. So when certain an investment consistently provides equal yield, regardless of the changes in market circumstances, it will not correlate with other risky investments whose yields vary with changing in market circumstances.

\subsection{Preconditions for free risk investments}

The free risk asset is an asset where the expected return is known with certainty. However, to be satisfying this consideration it needs to meet two essential conditions [3]:

- The first is that there isn't possibility of risk of non-payment. This condition, exclude all securities issued by private companies, because even in the case of the the largest and most reliable companies there is a certain probability to occur bankruptcy and to prevent the payment of obligations incurred. The only securities that are eligible to be risk-free are the government securities, not because the states are better managed by private companies, but that they control the printing of money, so in normal terms, they could to service their obligations. However, if such an assumption may sound unequivocally, it is not always possible to achieve, especially in situations where governments refuse to pay the liabilities created by some previous regimes and when they borrow in foreign currencies.

- To realize expected returns from some financial asset with certainty, it is necessary to exclude the reinvestment risk. To illustrate this claim, suppose that it is necessary to estimate the expected yield for the five-year period and is required to determine the risk free rate of return. Six-month treasury bills, even though it is free from the risk of non-payment, it is not risk-free because there is a reinvestment risk, so it is uncertain how much will be the market interest rate after six months. Even five-year bond can say that will not be risk-free, because the coupon interest will be reinvested at rates that can not be predicted in advance. So, the only choice for the risk free rate, will be a long-term zero coupon bond or in this particular instance five year zero coupon bond issued by government.

So, a financial asset (securities) can be risk-free only if it is issued by an entity that is exempt from the non-payment risk, and the selection of relevant securities that will be used to determine the risk free rate of return will depend from the period in that the return will be guaranteed.

Achieving requirements, non-payment risk and reinvestment risk to qualify an asset as a risk-free will mean that investment for different periods will have different risk free rates. Consequently, in determining the risk free rate for one-year cash flow will be a used one-year bond that is free from non-payment risk or five-year bond that is free from the risk of non-payment for five-year cash flow.

As previously indicated, the use of long-term bonds will not mean that we will get risk free rate for the relevant period, even if it is issued by an entity which is exempt from the non payment risk, because the coupon interest payable every six months would reinvest at rates whose amount is uncertain. The solution to this problem is to use zero coupon bond. In such a case, the risk free rate for the appropriate investment period will be determined by the rate of return of the zero coupon bond that is exempt from nonpayment risk, with maturity equal to the investment period. For example, in the U.S. where the zero coupon bond issued by government traded several years, determining the risk free rate is a simple task. In this case, the free risk rate can be determined even not traded with zero coupon bond, with using the interest rate by coupon bonds.

\subsection{Currency impact on the risk free rate of return}

Although the interest rate on long-term risk-free bonds from non-payment can be considered as a risk free, its interest rate can easily be changed, depending on the currency used in the analysis. For example, in September 2012, the market interest rate on ten-year bond issued by the U.S. government amounted to 1.77\%.[4] Assuming that the bonds issued by the U.S. government is risk-free, the risk free rate denominated in the U.S. dollar will be $1.77 \%$. At the same time, the market interest rate on ten-year bonds issued by the government of Japan, denominated in Japanese yen amounted to $0.8 \%$. If it is assumed that the Japanese government will certainly fulfill the contractual obligations, the interest rate of $0.8 \%$, will be risk-free rate for the Japanese yen. Fig. 2 shows interest rates on ten-year bonds issued in different currencies by governments that have AAA or AA + rating by S\&P. 


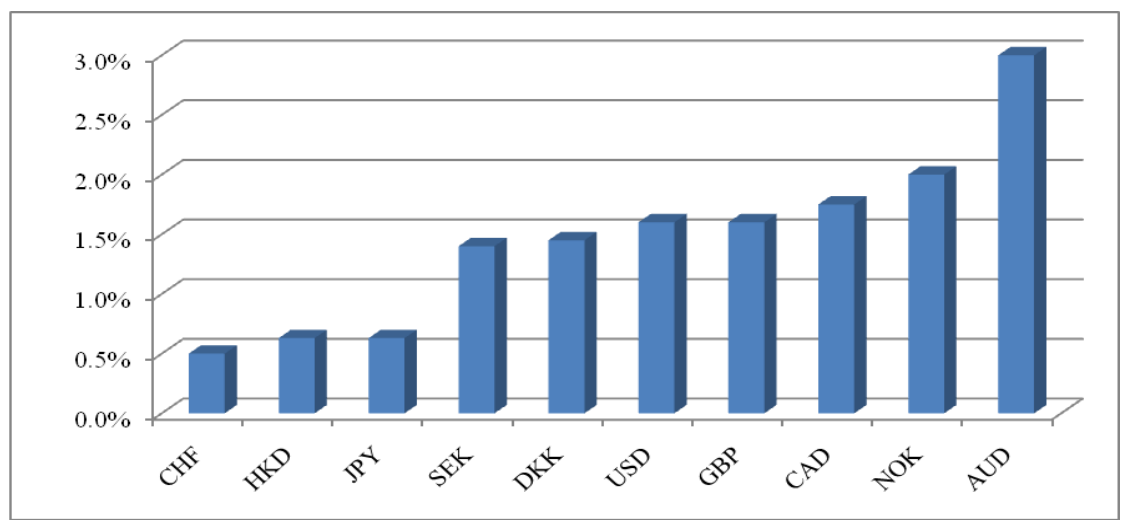

Figure 2 Interest rate on ten year government bond for some countries in world, September 2012[4]

In the list only missing Euro. There are at least 11 governments of the European Union that issue tenyear bonds denominated in Euro, but with different interest rates. Fig. 3 is a summary of interest rates on tenyear bonds in September 2012 in the euro area.

Since none of these governments technically has any control over the printing of euro, each of them is subject to a risk of non-payment. However, from a market point of view, there is a perception that the Greek and Portuguese bonds are more vulnerable to the risk of non payment than German and French bonds. To determine the risk free rate expressed in euros, will be used the lowest interest rate on ten-year euro bond. For example in September 2012, for risk-free rate of return would be taken interest rate $1.52 \%$ of the euro bond issued by German government. [6].

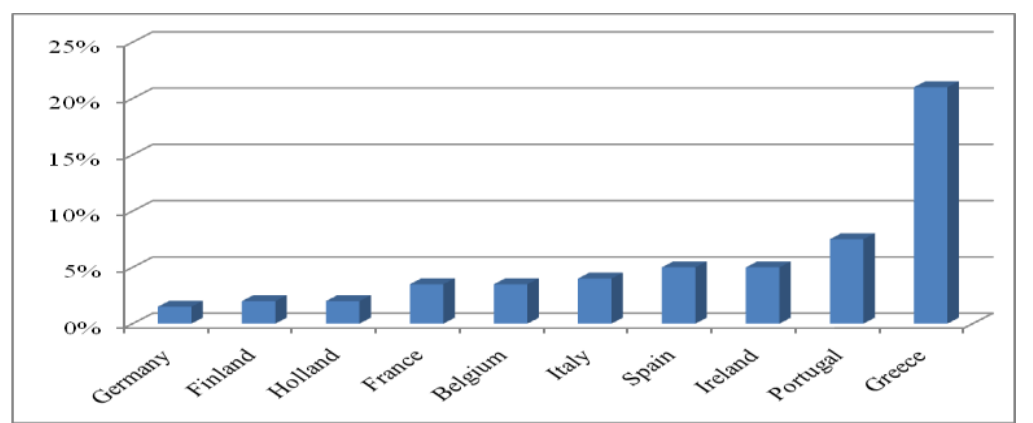

Figure 3 Interest rate of the ten years government bond in Eurozone [4]

So, the risk free rate of return in September 2012 would have varied between $0.59 \%$ for the Swiss franc to $3.11 \%$ for the Australian dollar [8]. Thereby impose two questions:

- Why risk free rate is different for different currencies? Since all interest rates specified as risk free, with the same maturity and free from the risk of non-payment, only significant factor that may cause a difference in the risk free rate is the expected inflation. Currencies that have higher rates of inflation have a higher risk-free rate than those with a low inflation rate. For example, taking the data in our example, it can be concluded that the market expects a higher rate of inflation in the Australian dollar than the U.S. dollar, which in turn is expected to have a higher rate of inflation than that of the Japanese yen.

- What risk-free rate should be used in the valuation process? Using higher risk free rate results in a higher discount rate, which reduces the present value of a cash flow, so that the use of the risk free rate for the Japanese yen will give a higher value for the company than using the risk free rate for the dollar. The fact that expected inflation is the main reason for the different level of risk free rates for different currencies, should be constantly borne in mind. If due to the allure of lower risk-free rate, the valuation of a company is made in Japanese yen, then the cash flows should be expressed in Japanese yen. If expected inflation of the Japanese yen is lower, then the expected growth rate and estimated cash flows expressed in Japanese yen will reflect low inflation. Consequently, all the benefits of using a lower discount rate for the Japanese yen will be terminated with the loss that it make when cash flows is denominated in Japanese yen.

So always there should be consistency between the currencies in which is calculated the risk free rate, with currency in which the cash flows whose present value is calculated, is expressed. For example, when the cash flows are valued in U.S. dollars in nominal value, then as the risk-free rate is used the interest rate on U.S. government bond, regardless of where is the company in analysis (it is from Brazil, India or Russia). How this may seem illogical, because these states have an increased risk of investment, risk free rate is not the mechanism through which the risk of these states is expressed. This also implies that the choice of the risk free rate does not 
depend on the company's country origin or where the project is implemented, but only of the currency in which are estimated expected cash flows. For example, the valuation of the company Nestle can be made using cash flows denominated in Swiss francs, with using the risk-free rate that is equal to the interest rate on long-term bonds issued by the Swiss government. Or, alternatively Nestle can be valued in British pounds, and in this case will be used cash flows denominated in British pounds and the risk free rate, which refers to the British pound.

If the difference in interest rates for two currencies does not reflect adequately the difference in expected inflation in these currencies, the current values obtained using different currencies will be different. In this sense, the specific case is when valued projects or assets will achieve greater value when is used currency with low interest rates in terms of inflation. In this case there is a risk, but at some point when interest rates will rise, it will correct this discrepancy, which will come to an equalization of values that are evaluated in different currencies.

\subsection{Inflation impact on the free risk rate of return}

In conditions of high and unstable inflation, it is necessary the valuation to be in real value. This implies that the estimation of cash flows is performed using real growth rates, excluding the growth that is the result of price inflation. In this case, to be a consistent approach, the discount rates used in the assessment should be expressed in real terms. Also, to get a real expected rate of return requires the application of a real risk-free rate of return. Although bonds can provide risk-free yield in nominal value, their yield is not risk-free in real terms because inflation can be variable. The real interest rate, which actually represents the best estimate of the real risk-free rate of return, is obtained by subtracting the expected inflation rate from the nominal interest rate.

When it comes to expressing the risk free rate of return in real terms, most relevant securities which may be used for its determination are the state securities indexed to inflation (Treasury Inflation Protected Securities - TIPS). These securities provide guaranteed real yield. For example, if a bond indexed to inflation has a real rate of return of 3\%, then $4 \%$ inflation at its nominal rate of return would be $7 \%$ or $5 \%$ if the inflation rate is $2 \%$.

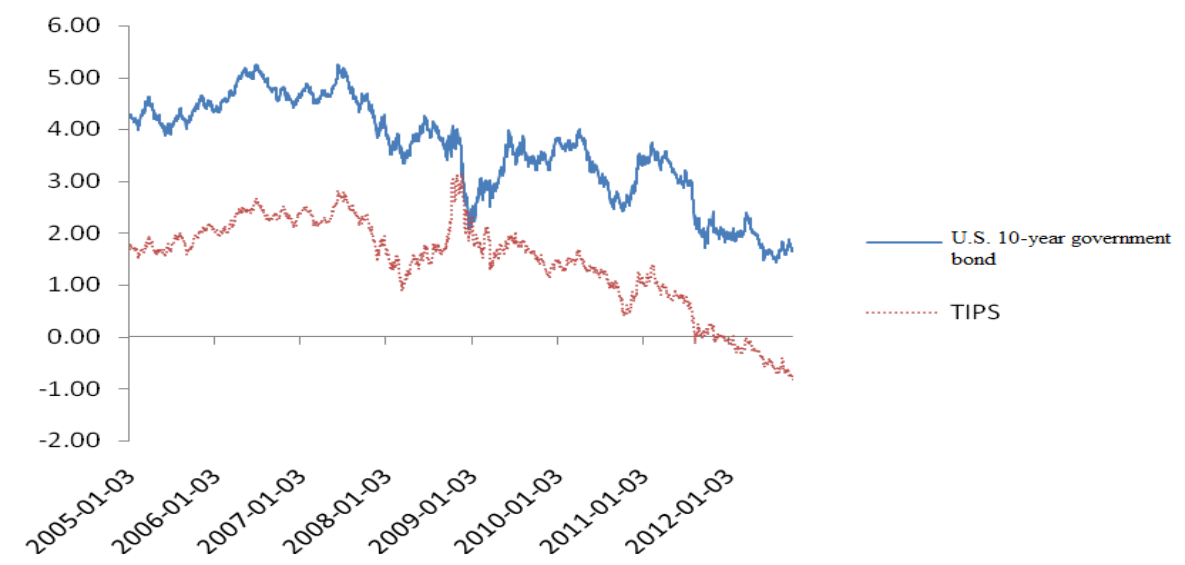

Figure 4 Interest rate on ten year american government bond and TIPS in period 2005-2012[9]

The difference between the nominal and the real rate of return on the government bonds, reflecting market expectations for the amount of the inflation. During the period shown in fig. 4 the average expected inflation rate is $1.39 \%$.

Rate of return on government bonds indexed to inflation can be used as risk free rate of return in developed capital markets (for example the United States). The only problem is that, in developed capital markets with stable and low expected inflation rate, the valuation is rarely done in real value. Markets where it is necessary to valuate at fair value, are those markets where there are not usually indexed securities exempt from the risk of non-payment. The real risk-free rates in these markets can be assessed taking into account the following assumptions [10]:

- As long as there is free movement of capital to the economies with the highest real rates of return, among the markets will not be any difference in the real risk-free rate of return. If realized this condition then the real risk-free rate of return in the United States estimated on the basis of bonds indexed to inflation, can be used as a real risk-free rate in any market.

- The second situation presents if there are restrictions on the movement of capital among markets. In this case, the expected real return in the economy on the long-term, should be equal to the expected real growth rate of the economy on the long term, to achieve the equilibrium. So, the real risk-free rate in a developed 
economy such as Germany, should be much lower than economies that have a high growth potential such as Hungari.

If apply a consistent approach, the estimated value of a company should be the same regardless of whether the discounted cash flow are discounted with real or nominal discount rate.

\section{CONCluSION}

Subject of research in the paper is the risk free rate of return. It is a starting point in determining the cost of capital. As the risk-free rate of return is treats the rate of return of an asset in which the realized yield does not vary around the expected returns, i.e. the standard deviation is 0 . Risk-free asset is also important to satisfy two conditions: there is no risk of non-payment and reinvestment risk in this asset. But also in determining the risk free rate of return is important to take into account the impact of currency. To allow an adequate assessment of the cost of capital, and thus the value of the firm is necessary for the analysis, risk free rate of return and cash flow can be expressed in the same currency. Also due to the impact of inflation on adequate assessment of the risk free rate of return, in the terms of inflation, the risk-free rate of return is determined by the rate of return of indexed government securities with inflation (Treasury Inflation Protected Securities - TIPS).

\section{REFERENCES}

[1] Reilly F. K., Brown K. C., Investment analysis and portfolio management, 7 (South-Western/Thomson Learning, Cincinnati Ohio, 2002).

[2] Damodaran A., Into the Abyss: What if nothing is risk free? SSRN, New York University - Stern School of Business, July, 2010.

[3] Damodaran A., What is the riskfree rate? A Search for the Basic Building Block, New York University -Stern School of Business, December, 2006.

[4] http://www.tradingeconomics.com/bonds-list-by-country.

[5] http://research.stlouisfed.org/fred2/graph/?id=DFII10 and http://research.stlouisfed.org/fred2/graph/?id=DGS10

[6] Damodaran A., The dark side of valuation: valuing young, distressed and complex businesses, 2 (FT Press, Upper Saddle River, N.J., 2010). 